\title{
Hypoglycaemic and anorexigenic activities of an $\alpha$-amylase inhibitor from white kidney beans (Phaseolus vulgaris) in Wistar rats
}

\author{
M. A. Tormo*, I. Gil-Exojo, A. Romero de Tejada and J. E. Campillo \\ Department of Physiology, Faculty of Medicine, University of Extremadura, Apartado de Correos 108, 06071 Badajoz, \\ Spain
}

(Received 15 October 2003 - Revised 24 April 2004 - Accepted 20 July 2004)

\begin{abstract}
An inhibitor of $\alpha$-amylase was isolated and purified from an extract of white kidney beans (Phaseolus vulgaris). The acute oral administration of the inhibitor $(50 \mathrm{mg} / \mathrm{kg}$ body weight) to adult Wistar rats together with a starch load $(2 \mathrm{~g} / \mathrm{kg}$ body weight suspended in $\mathrm{NaCl}$ $(9 \mathrm{~g} / \mathrm{l})$ ) reduced the increase in glycaemia over the basal value ( $\mathrm{NaCl}, 222$ (SEM 49); inhibitor, 145 (SEM 16) mmol/l $\times 180 \mathrm{~min} ; P<0 \cdot 05$ ) without modifying the insulin response. On administering the inhibitor orally $(50 \mathrm{mg} / \mathrm{kg}$ body weight dissolved in $\mathrm{NaCl}(9 \mathrm{~g} / \mathrm{l}))$ for $21 \mathrm{~d}$ to rats fed on a standard diet, a decline was observed in the glycaemia values on day 0 ( $\mathrm{NaCl}, 5.53$ (SEM 0.12); inhibitor, $5 \cdot 25$ (SEM 0.16) $\mathrm{mmol} / \mathrm{l}$ ) relative to those obtained on days 10 ( $\mathrm{NaCl}, 5.00$ (SEM 0.14); inhibitor, 4.60 (SEM 0.08) mmol/l; $P<0 \cdot 05$ ) and 21 (NaCl, 5.22 (SEM 0.22 ); inhibitor, 4.50 (SEM 0.12 ) mmol/l; $P<0.01$ ) of treatment, without modifying the plasma concentration of insulin. There was found to be a significant anorexigenic action of the inhibitor; there was reduced food intake ( $\mathrm{NaCl}, 23.07$ (SEM 0.31); inhibitor, 19.50 (SEM 0.49) g/ $\mathrm{d} ; P<0 \cdot 01$ ), a reduced weight gain ( $\mathrm{NaCl}, 52$ (SEM 3); inhibitor, -1.33 (SEM 8.9) g/21 d; $P<0 \cdot 01$ ), as well as changes in the activity of some intestinal enzymes such as maltase ( $\mathrm{NaCl}, 87$ (SEM 7); inhibitor, 127 (SEM 11) U/g proteins; $P<0 \cdot 05$ ). The present study has shown, for the first time, that the prolonged administration of an $\alpha$-amylase inhibitor reduces blood glucose levels and body-weight gain in Wistar rats.
\end{abstract}

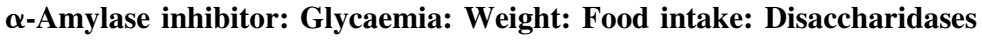

Inhibitors of $\alpha$-amylase have been detected in many cereals and some pulses (Bowman, 1945; Jaffe \& Lette, 1968; Marshall \& Lauda, 1975; Mulimani \& Rudrappa, 1994). In particular, the kidney bean (Phaseolus vulgaris) contains high levels of the inhibitor (Pusztai, 1966; Whitaker et al. 1988; Moreno et al. 1990). Elevated levels of ingestion of these raw foods lead to intestinal and metabolic alterations in man and in other animals (Rosenberg, 1982; Maranesi et al. 1984; Pusztai et al. 1995). The use in the early 1980s of crude extracts of kidney beans as starch blockers to control obesity and non-insulin-dependent diabetes mellitus was unsuccessful due to the low inhibitor content (BoLinn et al. 1982; Liener et al. 1984) and the presence of lectins and trypsin inhibitors in those extracts (Rosenberg, 1982). Subsequent human studies showed that a perfusion of the partially purified inhibitor in the duodenum significantly inhibited amylase activity during the ingestion of a starch diet (Layer et al. 1985). Ingestion of the purified inhibitor together with $50 \mathrm{~g}$ starch was found to reduce postprandial glycaemia levels in both healthy and diabetic subjects (Layer et al. 1986a). The long-term effect of the inhibition of intraluminal amylase activity in the gastrointestinal tract is, however, poorly understood.

The present study investigated the effect of the acute and chronic administration of an $\alpha$-amylase inhibitor $(\alpha-\mathrm{AI})$ isolated and purified from white kidney beans on the levels of glycaemia and insulinaemia, body weight, food intake, weight and length of the gastrointestinal tract, and disaccharidase activity of the brush-border membrane of enterocytes in rats.

\section{Materials and methods \\ Purification of the amylase inhibitor}

Purification of the $\alpha$-AI was performed following the method described by Pusztai et al. (1995). Basically, bean meal $(1 \mathrm{~kg})$ was mixed in 10 litres acetic acid (20 mmol/l) containing $0 \cdot 2 \mathrm{~g}$ ascorbic acid/l by stirring for $30 \mathrm{~min}$, and, after adjusting to $\mathrm{pH} 5.0$ with $1 \mathrm{M}$ $\mathrm{NaOH}$, the slurry was stirred for another $2 \mathrm{~h}$. After being left to stand in a cold room overnight, the extract was centrifuged (10000 $\mathrm{g}$ for $15 \mathrm{~min}$ ), $1.5 \mathrm{~g} \mathrm{CaCl}_{2}$ was added to clear the supernatant fraction and this was adjusted to $\mathrm{pH} 9.0$ with $1 \mathrm{M}-\mathrm{NaOH}$. After again being left to stand in a cold room overnight, the precipitate formed was removed by centrifugation $(3000 \mathrm{~g}$ for $10 \mathrm{~min})$ and the supernatant fraction adjusted to $\mathrm{pH} 3.8$ with $1 \mathrm{M}-\mathrm{HCl}$. After another night in a cold room, the extract was cleared by centrifugation $(10000 \mathrm{~g}$ for $15 \mathrm{~min}$ ) and diluted 2 -fold 
with distilled water. The diluted supernatant fraction was further purified by ion-exchange chromatography on a Sulfopropyl Fast Flow (Amersham Pharmacia Biotech, Sant Cugat del Valles, Barcelona, Spain) column $(50 \mathrm{~mm} \times 75 \mathrm{~mm}, 150 \mathrm{ml}$ bed volume) equilibrated with $25 \mathrm{M}$-sodium formate buffer $(\mathrm{pH} \mathrm{3.8)}$ ). After the extract had passed through, the column was rinsed with formate buffer until the extinction value at $280 \mathrm{~nm}$ fell below $0 \cdot 01$, and then the $\alpha$-AI was eluted with $0 \cdot 15 \mathrm{M}-\mathrm{NaCl}$ in a formate buffer. The $\alpha$-AI fractions from several chromatograms were combined and re-chromatographed through the Sulfopropyl Fast Flow column under the same conditions. To remove small-molecular-weight impurities, the concentrated eluates from the column were passed through a Sephacryl-100 column (Amersham Pharmacia Biotech, Sant Cugat del Valles, Barcelona, Spain) equili-

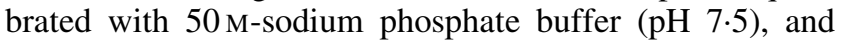
the first peak containing $\alpha$-AI was collected, dialysed against water, and freeze-dried. The yield was about $1.5-2.4 \mathrm{~g} \alpha-\mathrm{AI} / \mathrm{kg}$ bean meal.

\section{Test of $\alpha$-amylase inhibitor purity}

The haemagglutination activity of the $\alpha$-AI preparations was measured according to a previously reported method (Le Berre-Anton et al. 1997). Briefly, in U-bottomed microtitration plates, $25 \mu \mathrm{l}$ of 2 -fold serial dilutions of $\alpha$-AI $(1 \mathrm{mg} / \mathrm{ml})$ in $100 \mathrm{~mm}$-Tris, $150 \mathrm{~mm}-\mathrm{NaCl}$ buffer $(\mathrm{pH}$ 7.4) were mixed at room temperature with an equal volume of a $1 \%(\mathrm{v} / \mathrm{v})$ suspension of thrice-washed human $\mathrm{O} \mathrm{Rh}+$ erythrocytes in the same buffer. Haemagglutination was read $2 \mathrm{~h}$ later at room temperature and (as a control) after being left to stand at $4^{\circ} \mathrm{C}$ for $12 \mathrm{~h}$.

A polyacrylamide gel electrophoresis was carried out using the Miniprotean II System (Bio-Rad Laboratories, Alcobendas, Madrid, Spain) with $15 \%$ acrylamide gel (Pusztai et al. 1988).

\section{Animal experiments}

Animals. Adult (2.5 months) male Wistar rats $(363 \pm 11 \mathrm{~g}$ body weight) from our inbred colony were used. They had been maintained on a standard diet (maintenance diet; Panlab S.L., Barcelona, Spain; $61.41 \%$ (w/w) carbohydrate (100\% starch), $3.96 \%$ fibre, $15.06 \%$ protein, and $2.66 \%$ fat) with free access to food and water, and housed in a room at $24^{\circ} \mathrm{C}$ with lighting from 08.00 to 20.00 hours. The animals were cared for in accordance with the principles of the Guide to the Care and Use of Experimental Animals (Real Decreto, 1988), and the protocol was approved by the animal ethics committee of the University of Extremadura.

Acute effect. Blood glucose and plasma insulin (immunoreactive insulin; IRI) were determined at 09.00 hours (time 0 ) after $18 \mathrm{~h}$ fasting. Then, without anaesthesia, using a gastric cannula attached to a syringe, starch $(2 \mathrm{~g} / \mathrm{kg}$ body weight, soluble potato starch; Sigma, Alcobendas, Madrid, Spain) was administered orally at $50 \%$ in $\mathrm{NaCl}$ $(9 \mathrm{~g} / \mathrm{l})$ alone or with $\alpha$-AI at the dose of $50 \mathrm{mg} / \mathrm{kg}$ body weight. Measurements of blood glucose and IRI were made at 15, 30, 60, 90, 120, 150, and $180 \mathrm{~min}$. Blood was extracted from the tail of the animal and the blood glucose concentration was determined at the time of extraction from $2 \mu \mathrm{l}$ blood with reactive strips read in a Glucocard Memory (A. Menarini Diagnostics, Barcelona, Spain). The rest of the blood was collected in pre-heparinised tubes and centrifuged. The plasma was stored at $-70^{\circ} \mathrm{C}$ until the insulin assay.

Chronic effect. $\alpha$-AI ( $50 \mathrm{mg} / \mathrm{kg}$ body weight) dissolved in $\mathrm{NaCl}(9 \mathrm{~g} / \mathrm{l})$ was administered through a gastric cannula in a single dose at 20.30 hours over a period of $21 \mathrm{~d}$ to the 2.5-month-old Wistar rats. Every day at 09.00 hours during this experimental period, food and water intake and body weight were determined, and blood glucose was measured immediately as described earlier. Also, on days 10 and 21 of the experimental period, blood samples were extracted and prepared as described earlier for the plasma IRI assay.

After $21 \mathrm{~d}$ of treatment, the rats were killed in the morning by pentobarbital overdose. The abdomen was cut open, and the small intestine, pancreas, liver, and large intestine were removed, rinsed with $\mathrm{NaCl}(9 \mathrm{~g} / \mathrm{l})$, blotted dry, and weighed. The small intestine was measured under $5 \mathrm{~g}$ tension. Epithelial cells of the small intestine were isolated according to the method of Watford et al. (1979). This method allows the isolation of metabolically competent enterocytes, and is based on the use of EDTA and gentle mechanical treatment of the small-intestine mucosa. The isolated cells were used to determine disaccharidases.

\section{Analytical methods}

To measure the in vitro inhibition of the amylase activity of the porcine amylase by the $\alpha$-AI, the $\alpha$-AI was dissolved in $0.02 \mathrm{M}$-sodium phosphate buffer ( $\mathrm{pH}$ 6.9) containing $\mathrm{NaCl}(9 \mathrm{~g} / \mathrm{l})$, mixed with porcine pancreatic $\alpha$-amylase (type I-A; Sigma-Aldrich Química S.A., Alcobendas, Madrid, Spain), and incubated for $30 \mathrm{~min}$ at $37^{\circ} \mathrm{C}$ to allow formation of the inhibitor-enzyme complex. The amount of uninhibited $\alpha$-amylase was then determined using an amylase diagnostic kit (Dipal; Inquebor S.L., Granada, Spain) following the method of Wallenfels et al. (1978). The disaccharidase (maltase and sucrase) activity was determined in isolated epithelial cells, following the method of Dahlqvist (1964). The protein concentration was determined by the micro-Lowry method (SigmaAldrich Química, Alcobendas, Madrid, Spain). IRI was determined by RIA with a rat insulin kit which uses a specifically synthesized antibody against rat insulin (DRG's Instrument GmbH, Marburg, Germany).

\section{Calculation, expression of results and statistical analysis}

In the studies of the acute effect, the increment of blood glucose and IRI concentration were calculated planimetrically. Values are expressed as the mean and standard error of the mean. Statistical analyses were performed using the program InStat for Macintosh version 1.12. Repeated-measures ANOVA was used to assess changes in the level of glycaemia and IRI during the treatment in the same experimental group. When $P<0.05$, the significance of the difference was estimated by the Bonferroni test. The Mann-Whitney U test was used to determine 
differences between the groups. A $P$ value of less than 0.05 was considered statistically significant.

\section{Results}

The in vitro $\alpha$-amylase activity was suppressed by $70 \%$ with $0.15 \mathrm{mg} \alpha-\mathrm{AI} / \mathrm{ml}$ and by $94 \%$ with $1.5 \mathrm{mg} \alpha-\mathrm{AI} / \mathrm{ml}$ (Fig. 1). Fig. 2 shows that the oral administration of the starch overload ( $2 \mathrm{~g} / \mathrm{kg}$ body weight) led to an increase in glycaemia. The maximum value was attained at $50 \mathrm{~min}$ after administration. The level remained above the basal value throughout the study period. The simultaneous administration of starch and inhibitor $(50 \mathrm{mg} / \mathrm{kg}$ body weight) led to a reduction in glycaemia values. The reduction was found to be statistically significant $(P<0 \cdot 05)$ in comparing the increase in glycaemia over the basal value (blood glucose

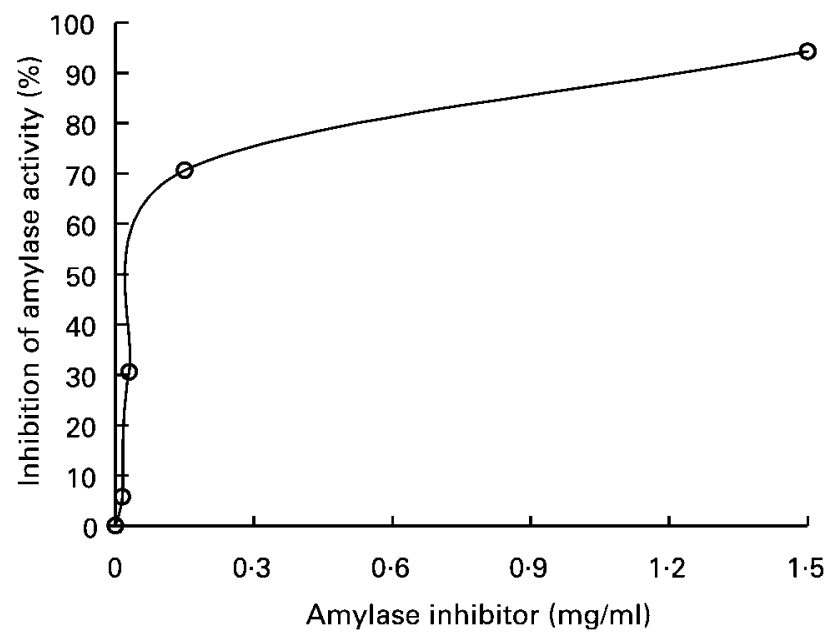

Fig. 1. In vitro inhibition of porcine pancreatic $\alpha$-amylase activity by the $\alpha$-amylase inhibitor purified from white kidney beans (Phaseolus vugaris). The values are means of four determinations.

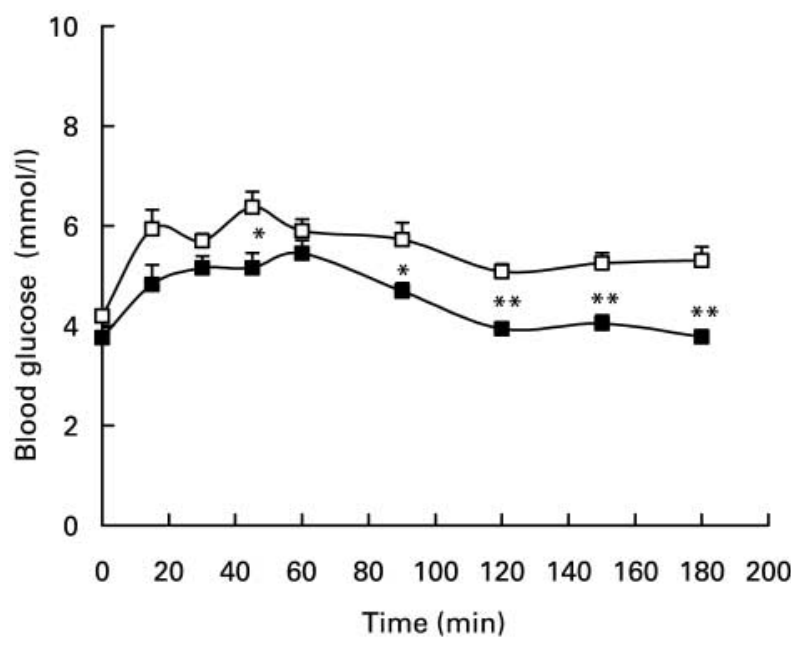

Fig. 2. Blood glucose values $(\mathrm{mmol} / \mathrm{l})$ obtained after the oral administration to 2.5 -month-old Wistar rats of starch $(2 \mathrm{~g} / \mathrm{kg}$ body weight) suspended at $50 \%$ in $\mathrm{NaCl}(9 \mathrm{~g} / \mathrm{l})$ alone $(\mathrm{NaCl} ; \square)$ or with $50 \mathrm{mg} \alpha-$ amylase inhibitor/kg body weight $(\square)$. The values are means of six determinations for each experimental group, with standard errors of the mean represented by vertical bars. Mean value was significantly different from that for $\mathrm{NaCl}$ at the same time: ${ }^{\star} P<0.05,{ }^{* \star} P<0.01$ area under the curve) with (145 (SEM 16)) or without (222 $($ SEM 49$) \mathrm{mmol} / \mathrm{l} \times 180 \mathrm{~min})$ the inhibitor. The differences in total insulin secretion response (IRI area under the curve) with (18.15 (SEM 1.33)) and without (16.20 (SEM $0.92) \mathrm{ng} / \mathrm{ml} \times 180 \mathrm{~min})$ the inhibitor were not statistically significant.

The oral administration of the inhibitor $(50 \mathrm{mg} / \mathrm{kg}$ body weight dissolved in $\mathrm{NaCl}(9 \mathrm{~g} / \mathrm{l}))$ over $21 \mathrm{~d}$ at 20.30 hours to rats allowed free access to a standard diet was followed by a slight reduction in glycaemia values with respect to day 0 . This reduction was significant $(P<0.01)$, except for days 8,10 , and 16 when the significance level was $P<0.05$ from day 4 of treatment until the end of the study (Fig. 3). No significant changes were observed in glycaemia levels in the group of rats who were administered $\mathrm{NaCl}(9 \mathrm{~g} / \mathrm{l})$ alone, for any of the days of the study. There were significant differences in the glycaemia of the treated rats on days $10(P<0.05)$ and $21(P<0.01)$ with respect to the untreated rats on those same days. There was no significant reduction in IRI $(\mathrm{ng} / \mathrm{ml})$ in the $\alpha$-AItreated rats on days $10(2.46$ (SEM 0.27$))$ and $21(2.23$ (SEM 0.17)) with respect to day 0 (2.72 (SEM 0.58)). Also, there were no significant differences in these insulinaemia levels with respect to those measured on days 0 (2.75 (SEM 0.48)), $10(3.23$ (SEM 0.38)), and $21(3.38$ (SEM $0 \cdot 67)$ ) of the untreated rats.

During the chronic administration of the inhibitor, there was no reduction in water intake (Table 1), but there was a significant reduction in daily food intake. This anorexigenic effect of the inhibitor was reflected in a smaller weight increase of the rats administered the inhibitor $(-1.33$ (SEM 8.9) g weight gain at $21 \mathrm{~d})$ relative to the controls (52 (SEM 3) g weight gain at $21 \mathrm{~d} ; P<0 \cdot 01$ ).

The $\alpha$-AI treatment over $21 \mathrm{~d}$ significantly reduced the weight of the small intestine, the large intestine, liver, and pancreas (Table 2). There was a significant increase

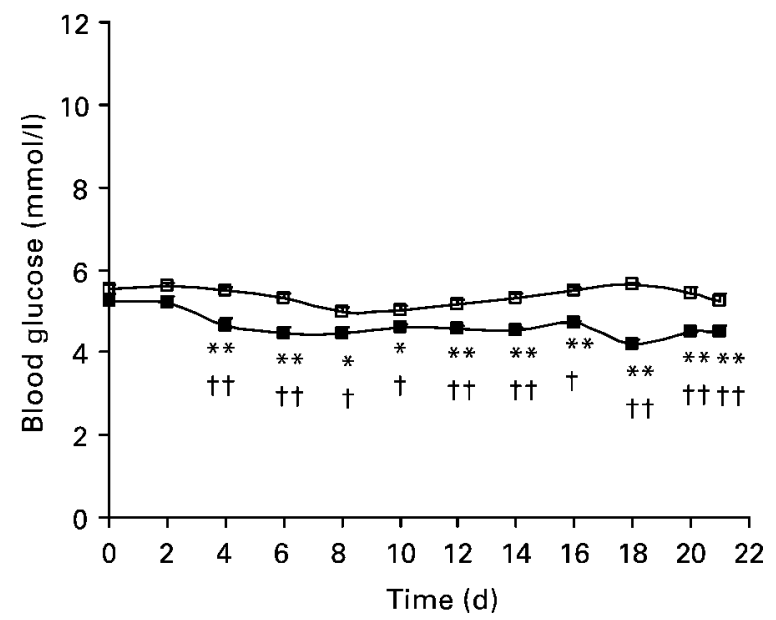

Fig. 3. Evolution of the blood glucose values $(\mathrm{mmol} / \mathrm{l})$ of Wistar rats over the $21 \mathrm{~d}$ following the oral administration of $\mathrm{NaCl}(9 \mathrm{~g} / \mathrm{l})$ alone $(\mathrm{NaCl} ; \square)$ or containing $50 \mathrm{mg} \alpha$-amylase inhibitor/kg body weight (घ). The values are means of six determinations for each experimental group, with standard errors of the mean represented by vertical bars. Mean value was significantly different from that for $\mathrm{NaCl}$ on the same day: ${ }^{\star} P<0.05,{ }^{\star \star} P<0.01$. Mean value was significantly different from that for inhibitor on day 0 : $\uparrow P<0.05$, $\uparrow \uparrow P<0.01$. 
Table 1. Intake of water and food, and body-weight gain over the time of the experimental period, of $2 \cdot 5$-month-old Wistar rats subjected for $21 \mathrm{~d}$ to a treatment with an inhibitor of pancreatic amylase isolated from white kidney beans (Phaseolus vugaris) $(50 \mathrm{mg} / \mathrm{kg}$ body weight) suspended in $\mathrm{NaCl}(9 \mathrm{~g} / \mathrm{l}) \dagger$

(Mean values and standard errors of the mean)

\begin{tabular}{llllll}
\hline & \multicolumn{2}{c}{$\mathrm{NaCl}(n$ 6) } & & \multicolumn{2}{c}{ Inhibitor $(n 6)$} \\
\cline { 2 - 3 } & Mean & SEM & & Mean & SEM \\
\hline Water $(\mathrm{ml} / \mathrm{d})$ & 31.08 & 1.15 & & 30.30 & 0.67 \\
Food $(\mathrm{g} / \mathrm{d})$ & 23.07 & 0.31 & & $19.50^{\star *}$ & 0.49 \\
Body-weight gain $(\mathrm{g} / 21 \mathrm{~d})$ & 52 & 3 & & $-1.33^{\text {** }}$ & 8.9
\end{tabular}

** Mean value was significantly different from that for $\mathrm{NaCl}(P<0.01)$.

†For details of diets and procedures, see p. 786 .

$(P<0 \cdot 05)$ in maltase activity, but not in sucrase activity measured in the enterocytes isolated from the small intestine at the end of the $21 \mathrm{~d}$ of treatment with the inhibitor (Table 3).

\section{Discussion}

\section{Method and purification yield}

The $\alpha$-AI preparations contained four polypeptide bands of $32,29,17$, and $16 \mathrm{kDa}$, similar to the results reported by

Table 2. Length and weight of the small intestine and weights of the liver, pancreas, and large intestine of Wistar rats which had been subjected to $21 \mathrm{~d}$ of treatment with an $\alpha$-amylase inhibitor from kidney beans (Phaseolus vugaris) $(50 \mathrm{mg} / \mathrm{kg}$ body weight) suspended in $\mathrm{NaCl}(9 \mathrm{~g} / \mathrm{l}) \dagger$

(Mean values and standard errors of the mean)

\begin{tabular}{|c|c|c|c|c|}
\hline & \multicolumn{2}{|c|}{$\mathrm{NaCl}(n 6)$} & \multicolumn{2}{|c|}{ Inhibitor (n 6) } \\
\hline & Mean & SEM & Mean & SEM \\
\hline $\begin{array}{l}\text { Length of small intestine } \\
(\mathrm{mm})\end{array}$ & 1250 & 40 & 1230 & 10 \\
\hline $\begin{array}{l}\text { Weight of small intestine } \\
\text { (g) }\end{array}$ & $11 \cdot 30$ & 0.50 & $8 \cdot 97^{\star \star}$ & 0.21 \\
\hline Liver $(\mathrm{g})$ & $16 \cdot 60$ & 0.87 & $14 \cdot 47^{\star}$ & 0.47 \\
\hline Pancreas (g) & $1 \cdot 16$ & 0.13 & $0.68^{*}$ & 0.07 \\
\hline Large intestine (g) & 3.85 & 0.17 & $3 \cdot 13^{*}$ & 0.11 \\
\hline
\end{tabular}

Mean value was significantly different from that for $\mathrm{NaCl}:{ }^{\star} P<0.05$, ${ }^{\star \star} P<0.01$.

†For details of diets and procedures, see p. 786

Table 3. Disaccharidase activity (sucrase and maltase) measured in enterocytes isolated from the small intestine of Wistar rats which had been subjected to $21 \mathrm{~d}$ of treatment with an $\alpha$-amylase inhibitor from kidney beans (Phaseolus vugaris) $(50 \mathrm{mg} / \mathrm{kg}$ body weight) suspended in $\mathrm{NaCl}(9 \mathrm{~g} / \mathrm{l}) \dagger$

(Mean values and standard errors of the mean)

\begin{tabular}{lccccr}
\hline & \multicolumn{2}{c}{$\mathrm{NaCl}(n 6)$} & & \multicolumn{2}{c}{ Inhibitor $(n 6)$} \\
\cline { 2 - 3 } \cline { 5 - 6 } & Mean & SEM & & Mean & SEM \\
\hline Sucrase (U/g protein) & 42 & 6 & & 34 & 6 \\
Maltase (U/g protein) & 87 & 7 & & $127^{\star}$ & 11 \\
\hline
\end{tabular}

* Mean value was significantly different from that for $\mathrm{NaCl}(P<0.05)$. †For details of diets and procedures, see p. 786 other workers (Le Berre-Anton et al. 1997). The test for haemagglutination activity showed no evidence of contamination of the $\alpha$-AI preparation with kidney bean lectin; again, results that were similar to previous reports (Maranesi et al. 1984; Pusztai et al. 1995).

\section{Hypoglycaemic effect}

The results show that the $\alpha$-AI isolated and purified from white kidney beans significantly reduces glycaemia levels in rats following both acute (reduction of postprandial glycaemia) and chronic (reduction of basal glycaemia) administration. Similar results have been described by other workers for growing non-diabetic Wistar rats (Kotaru et al. 1989), and for healthy and type-2 diabetic subjects (Layer et al. 1986a,b; Boivin et al. 1987; Jain et al. 1989, 1991). These previously reported studies were all carried out under acute conditions, for which reason the present study was designed to investigate the effect of the prolonged daily administration of the $\alpha$-AI.

The results showed no significant changes in plasma insulin levels after $\alpha$-AI treatment, whether with acute or chronic administration, although the values were apparently lower. Other workers (Kotaru et al. 1989) have reported similar findings, with a decline in plasma insulin levels after the administration of $\alpha$-AI purified from the cranberry bean variety of $P$. vulgaris together with an experimental diet in growing male Wistar rats. Healthy and diabetic subjects (Layer et al. 1986a,b), who were administered $50 \mathrm{~g}$ starch together with $10 \mathrm{~g}$ inhibitor, presented reduced levels of postprandial plasma insulin and $\mathrm{C}$-peptide during the time that glucose levels were greater than the fasting levels.

\section{Intake of water and food and body weight}

The present results demonstrated that the chronic administration of $\alpha$-AI reduces food intake and weight gain. As the $\alpha$-AI was administered by a gastric cannula the anorexigenic effect observed could not be attributed to a lack of palatability of the product reducing the energy intake.

A similar anorexigenic effect has been known for many years (Jaffe \& Lette, 1968; Puls \& Kneup, 1973; Pusztai et al. 1995). Indeed, different preparations based on the inhibitor isolated from $P$. vulgaris are commercially available in the USA for the treatment of obesity. One of them is manufactured under the supervision of $\mathrm{J}$. J. Marshall who, with C. Lauda, was the first to purify and characterise $\alpha$-AI (Marshall \& Lauda, 1975), which they denominated phaseolamin. It has also been difficult to explain how the chronic administration of $\alpha$-AI reduces food intake. Studies on human subjects have shown that the inhibition of pancreatic amylase is associated with a delay in gastric emptying, and that the arrival of a greater amount of undigested carbohydrates in the ileum also slows gastric emptying (Jain et al. 1989, 1991). One must therefore agree with the suggestions of other workers who studied an $\alpha$-AI purified from wheat (Kataoka \& DiMagno, 1999) that it is most likely that amylase inhibition produces satiety and decreases food intake by delaying gastric emptying, and that the weight loss caused by the inhibitor is due to that 
satiety rather than to any alterations in the small intestine. As did those previous workers, in the present study too, no signs of malabsorption were observed, such as diarrhoea or increase in stools (data not shown), although the dose used by those workers was larger than in the present case. This seems to be an interesting finding, since $\alpha$-glucosidases often cause diarrhoea and other collateral effects. Adequate amylase inhibition, however, could delay intestinal absorption and reduce body weight by diminishing food intake without malabsorption (Kataoka \& DiMagno, 1999).

\section{Tissue weight}

The chronic administration of $\alpha$-AI led to weight and length changes in the gastrointestinal tract as well as in other organs such as the liver and the pancreas. Specifically, a decrease was observed in the absolute weight of the small and large intestines. On the contrary, other workers (Pusztai et al. 1995), administering different doses of $\alpha$-AI also purified from white kidney beans (10, $20,40 \mathrm{~g} / \mathrm{d}$ ) to 19 -d-old Wistar rats, observed a slight but significant increase in the weight of the small intestine, with an even more pronounced increase in weight of the caecum. According to those authors, this is clearly the consequence of poor breakdown of the dietary starch in the small intestine and its accumulation in the caecum. With respect to the liver and the pancreas, their absolute weight was less in the $\alpha$-AI-treated rats, and similar to the values reported by other workers (Pusztai et al. 1995), although in that study the differences were only significant in the case of the liver and with the highest doses of the inhibitor.

\section{Disaccharidase activity}

Changes were also observed in the enzymic activity of maltase but not of sucrase as measured in enterocytes isolated from the small intestine at the end of the experimental period. Similar results have been described (Kataoka \& DiMagno, 1999) in homogenates of the distal intestine of growing rats who ingested the inhibitor purified from wheat, together with food intake for $21 \mathrm{~d}$. The chronic inhibition of intraluminal amylase activity increases the amount of unabsorbed carbohydrates reaching the distal intestine and increases the expression of disaccharidases in the distal small intestine (Kataoka \& DiMagno, 1999). The interpretation of these authors is that the delivery of unabsorbed carbohydrate to the distal small intestine increases disaccharidase activities in the distal intestine.

These changes, together with the effect of the inhibitor itself, could cause a delay in glucose entering the bloodstream from the intestine without there being the symptoms of malabsorption that are observed in some patients with the administration of $\alpha$-glucosidase inhibitors.

In conclusion, the results of the present study have shown that the chronic administration to adult Wistar rats of an inhibitor purified from white kidney beans decreases the levels of glycaemia without significantly altering insulinaemia levels, reduces food intake and body-weight gain, and increases maltase activity in enterocytes isolated after
$21 \mathrm{~d}$ of treatment. This could be of use in the treatment of obesity and diabetes.

\section{Acknowledgements}

The present study was supported by grants from the Spanish 'Comisión Interministerial de Ciencia y Tecnología' (CICYT) no. ALI98-0706 and from the 'Junta de Extremadura-Consejería de Educación y Fondo Social Europeo' (no. IPR00C037). The authors are very grateful to Dr F. Henao for helpful discussions and for the critical reading of the manuscript, and to A. Alonso for technical assistance.

\section{References}

Boivin M, Zinsmeister AR, Go VL \& DiMagno EP (1987) Effect of a purified amylase inhibitor on carbohydrate metabolism after a mixed meal in healthy humans. Mayo Clin Proc 62, 249-255.

Bo-Linn GW, Santa Ana CA, Morawski SG \& Fordtran JS (1982) Starch blockers - their effect on calorie absorption from a highstarch meal. N Engl J Med 307, 1413-1416.

Bowman DE (1945) Amylase inhibitor of navy bean. Science $\mathbf{1 0 2}$, $358-359$.

Dahlqvist A (1964) Method for assay of intestinal disaccharidases. Anal Biochem 7, 18-25.

Jaffe WG \& Lette CL (1968) Heat-labile growth-inhibiting factors in beans (Phaseolus vulgaris). J Nutr 94, 203-210.

Jain NK, Boivin M, Zinsmeister AR, Brown ML, Malagelada JR \& DiMagno EP (1989) Effect of ileal perfusion of carbohydrates and amylase inhibitor on gastrointestinal hormones and emptying. Gastroenterology 96, 377-387.

Jain NK, Boivin M, Zinsmeister AR \& DiMagno EP (1991) The ileum and carbohydrate-mediated feedback regulation of postprandial pancreaticobiliary secretion in normal humans. Pancreas 6, 495-505.

Kataoka K \& DiMagno EP (1999) Effect of prolonged intraluminal alpha-amylase inhibition on eating, weight, and the small intestine of rats. Nutrition 15, 123-129.

Kotaru M, Iwami K, Yeh HY \& Ibuki F (1989) In vivo action of alpha-amylase inhibitor from cranberry bean (Phaseolus vulgaris) in rat small intestine. J Nutr Sci Vitaminol (Tokyo) 35, 579-588.

Layer P, Carlson GL \& DiMagno EP (1985) Partially purified white bean amylase inhibitor reduces starch digestion in vitro and inactivates intraduodenal amylase in humans. Gastroenterology 88, 1895-1902.

Layer P, Rizza RA, Zinsmeister AR, Carlson GL \& DiMagno EP (1986a) Effect of a purified amylase inhibitor on carbohydrate tolerance in normal subjects and patients with diabetes mellitus. Mayo Clin Proc 61, 442-447.

Layer P, Zinsmeister AR \& DiMagno EP (1986b) Effects of decreasing intraluminal amylase activity on starch digestion and postprandial gastrointestinal function in humans. Gastroenterology 91, 41-48.

Le Berre-Anton V, Bompard-Gilles C, Payan F \& Rouge P (1997) Characterization and functional properties of the alpha-amylase inhibitor (alpha-AI) from kidney bean (Phaseolus vulgaris) seeds. Biochim Biophys Acta 1343, 31-40.

Liener IE, Donatucci DA \& Tarcza JC (1984) Starch blockers: a potential source of trypsin inhibitors and lectins. Am J Clin Nutr 39, 196-200.

Maranesi M, Carenini G \& Gentili P (1984) Nutritional studies on anti alpha-amylase: I) Influence on the growth rate, blood 
picture and biochemistry and histological parameters in rats. Acta Vitaminol Enzymol 6, 259-269.

Marshall JJ \& Lauda CM (1975) Purification and properties of phaseolamin, an inhibitor of alpha-amylase, from the kidney bean, Phaseolus vulgaris. J Biol Chem 250, 8030-8037.

Moreno J, Altabella T \& Chrispeels MJ (1990) Characterization of alpha-amylase inhibitor, a lectin like protein in the seeds of Phaseolus vulgaris. Plant Physiol 92, 703-709.

Mulimani VH \& Rudrappa G (1994) Effect of heat treatment and germination on alpha amylase inhibitor activity in chick peas (Cicer arietinum L.). Plant Foods Hum Nutr 46, 133-137.

Puls W \& Kneup U (1973) Influence of an amylase inhibitor (BAY d 7791) on blood glucose, serum insulin and NEFA in starch loading tests in rats, dog and man. Diabetologia 9, 97-101.

Pusztai A (1966) The isolation of two proteins, glycoprotein I and a trypsin inhibitor, from the seeds of kidney bean (Phaseolus vulgaris). Biochem J 101, 379-384.

Pusztai A, Grant G, Duguid T, Brown DS, Peumans WJ, Van Damme EJ \& Bardocz S (1995) Inhibition of starch digestion by alpha-amylase inhibitor reduces the efficiency of utilization of dietary proteins and lipids and retards the growth of rats. $J$ Nutr 125, 1554-1562.
Pusztai A, Grant G, Stewart JC \& Watt WB (1988) Isolation of soybean trypsin inhibitors by affinity chromatography on anhydrotrypsin-Sepharose 4B. Anal Biochem 172, $108-112$.

Royal Decree (1988) Real Decreto 223/1988 de 14 de marzo, sobre protección de los animales utilizados para experimentación y otros fines científicos (Royal Decree 223/1988, 14 March, Principles for care and use of experimental animals). BOE 67, 8509-8512.

Rosenberg IH (1982) Starch blockers - still no calorie-free lunch. $N$ Engl J Med 307, 1444-1445.

Wallenfels K, Foldi P, Nierman H, Bender H \& Linder D (1978) The enzymic synthesis, by transglucosylation of a homologous series of glycosidically substituted malto-oligo-saccharides, and their use as amylase substrates. Carbohydr Res 61, $359-368$.

Watford M, Lund P \& Krebs HA (1979) Isolation and metabolic characteristics of rat and chicken enterocytes. Biochem J 178, 589-596.

Whitaker JR, Filho FF \& Lajolo FM (1988) Parameters involved in binding of porcine pancreatic alpha-amylase with black bean inhibitor: role of sulfhydryl groups, chloride, calcium, solvent composition and temperature. Biochimie 70, 1153-1161. 